ORIGINAL ARTICLE

\title{
To investigate which antihypertensive drug is the most popular prescription amongst Physicians
}

\author{
MOHAMMAD MUSTAFA FAROOQ KHAN ${ }^{1}$, MUHAMMAD TALHA MUMTAZ ${ }^{2}$, MAHNOOR MOHYDIN ${ }^{3}$, SHAZIA ASIM${ }^{4}$, \\ WALI HAIDER ZAIDI ${ }^{5}$ \\ ${ }^{1}$ House Officer, Ghurki Trust Teaching Hospital, Lahore \\ ${ }^{2}$ Final Year Medical Student LMDC, Lahore \\ ${ }^{3}$ Medical Officer, Services Hospital, Lahore \\ ${ }^{4}$ Associate Professor, Pharmacology Department, Lahore Medical and Dental College, Lahore \\ ${ }^{5}$ House Officer, Ghurki Trust Teaching Hospital, Lahore \\ Correspondence to: Mohammad Mustafa Farooq Khan, Email: mftkhan1@gmail.com, Cell: 0331-4224802
}

\begin{abstract}
Background:Globally, hypertension has been recognized as a main health problem for under developed as well as developed countries. It can also be defined as a non- transmittable illness due to its high rate of death and delay in early diagnosis, it is called "silent killer". There are limited research findings available in Pakistan forassessing it'sprevalenceand no latest researches are carried out.

Objective: The main goal of current research is to investigate which antihypertensive drug is the most popular prescription amongst Physicians.

Material and Methods:It was a cross sectional descriptive studyperformed at the pharmacologysection, Lahore Medical and Dental College (LMDC). All adult participants $\left(20 \geq 50 \leq\right.$ years) for the period of $11^{\text {th }}$ to $20^{\text {th }}$ April 2017.After taking informed permission from all the participants were enrolled. A questionnaire was used to collect the dataand analyzed by using SPSS 20 . A comparative test was used to compute results.

Results:50 participants were interviewed for the survey. There were 25(50\%) males and 25(50\%) females in this research. The average age of the subject was $32.15 \pm 2.63$ years. There were $22(44 \%)$ married subjects, $15(30 \%)$ hypertensive and $11(22 \%)$ smokers in this research. $28(56 \%)$ study subject were suffering from genetically inherited hypertension. .Hypertensive patients were treated with one drug therapy $35(70 \%)$ as compare with multi drug $15(30 \%)$. Prescribed drug groups of ACE Inhibitors \& Beta-Blockers as $21(42 \%)$ and Diuretics given as $6(15 \%)$. Most popular drug prescribed by physicians in single drug was Captopril $11(22 \%)$ and in multi drug Spirolactone medicine was $12(24 \%)$.

Conclusion:There are several recommendations and pharmacologic treatments available for decreasing the morbidity and mortality associated with the disease. The most essential part of treatment hypertension, regardless of whatever medication is used, is lowering blood pressure. Physicians, other healthcare workers, and patients must communicate effectively for management of hypertension.
\end{abstract}

Key Words: ACE Angiotensin-converting enzyme LMDC

Lahore Medical and Dental College

\section{INTRODUCTION}

Hypertension also called elevated blood pressure is defined as long term medical condition where the blood pressure in the arteries is continuously high. Typically it produces no effects however it is associated with significant risk factors i.e. coronary heart attack, stroke, heart failure, peripheral artery disease progressive kidney disease and dementia.Despite the fact that hypertension is widely recognized as a major risk factor for cardiovascular disease and death, data on its prevalence in most developing countries is insufficient, which is required to estimate the economic cost of hypertension and to better allocate health resources to its diagnoses, therapy, and management. Many population-based surveys have been conducted in Pakistan during the last two-to- three decades. However, there are no nationwide estimates of hypertension prevalence or trends in prevalence over the previous few decades.

In the United States, hypertension affects around one out of every three individuals, over 2 million new cases diagnosed every year. Another $28 \%$ of the population in the United States is suffering from pre-hypertension while around $7 \%$ is unconscious about their illness. ${ }^{(1)} \mathrm{HTN}$ affects $>1000$ million people and expected to cross to 156000 million by the year 2025. It is the most common reason of mortality as well as second big cause of disability across the world. (2)

Many randomized controlled clinical studies have been conducted worldwide, the findings of these trials showed that the effective hypertension treatment reduces the risk of stroke, CAD, HF, renal failure, PVD and death. (3) The risk of developing these complications is continuous, starting at a blood pressure (BP) level as low as $115 / 75$ $\mathrm{mm} \mathrm{Hg}{ }^{(4)}$

Hypertension is the leading cause \& contributing factor in the development of cardiovascular illnesses across the world. Despite the availability of effective antihypertensive drugs and extensive research, substantial numbers of individuals in clinical practice nevertheless have uncontrolled hypertension. According to studies, control rates differ depending on the country and geographic location. ${ }^{(5)}$ Despite the fact that hypertension knowledge is high, ranging from 62 percent in Australia to 72 percent in the United States, control rates remain low, at 24 percent and 35 percent, respectively. In the South Asian area, the situation is more concerning, with China reporting just $8 \%$ control rates and India reporting only $6 \%$ control rates in the management of hypertension. Hypertension affects an estimated 1 billion individuals globally. ${ }^{(6)}$ 
To investigate which antihypertensive drug is the most popular prescription amongst Physicians

According to a survey conducted in Pakistanhypertension affects $18 \%$ of total population and $33 \%$ population over the age of 45 years. Another research showed that $18 \%$ Pakistanis have hypertension and every third person over the age of 40 developing the chance of different co-morbidities but reported only half of these hypertensive patients were treated. As a result, just 12.5 percent of hypertension patients were effectively managed $^{(6)}$. In distant locations, such as Balochistan, the awareness regarding hypertension disease not satisfactory and control rate is expected to worsen. ${ }^{(7)}$

Approximately $90 \%$ to $95 \%$ of individuals in the USA with high BP have no prominent reason for their disease. Renal dysfunction and renovascular disorders are the most prevalent causes among the $5 \%$ with known causes. Several factors have been identified as contributing to the high prevalence of uncontrolled hypertension.Along with unhealthy lifestyles, a poor understanding of hypertension, biased public health system and physicians who treating hypertension not accordingly established standardsguidelines. Uncontrolled hypertension can also be caused by noncompliance with antihypertensive treatment. In an outpatient environment at a tertiary care institution, $43 \%$ of patients were not entirely adherent to taking antihypertensive medicines. ${ }^{\left({ }^{8}\right)}$.

Committee on Prevention, Diagnosis, Control and Treatment of High BP supports diuretics as a first choice of treatment against hypertension. Nevertheless, strong clinical trial data suggests other drugs for treatment of hypertension, like angiotensin converting enzyme inhibitors (ACEIs), decrease hypertension consequences. (9) According to all popular guidelines, most individuals with hypertension require just one antihypertensive medication to achieve BP level that successfully decreases risks of comorbidities. (10) There is variety of medicines against hypertension prescribed by doctors worldwide. Calcium channel blockers (CCBs), Beta blockers (b-blockers), Angiotensin converting enzyme inhibitors (ACE)/Angiotensin receptor blockers (ARB), and diuretics are the most frequentlyadvised medicines for treatment of hypertension in many countries ${ }^{(11)}$.

\section{MATERIAL \& METHOD}

The research was done at the Pharmacology section, Lahore Medical \&Dental College (LMDC). All adult participants of age $20 \geq 50 \leq$ years for the period of $11^{\text {th }}$ April to $20^{\text {th }}$ April 2017, who were known hypertensive and using antihypertensive drugs for at least 42 days, were included. Antihypertensive drugs were advisedby experts. Those patients were excluded from researchwho failed to show documented proof.

Usage of multi antihypertensive medicine was primary outcome of the current research. Secondary outcome was use of diuretics against hypertension. Basic information, co morbidities, antihypertensive drug type number as well as average duration of using medicinewereobserved by statisticians.

SPSS version 21.0 was used forentry and compiling of the data. Mean $\pm S D$ was computed for numeric data whilenumbers and \%ages for categoricaldata. Chi square test and independent sample $t$ test was applied forcomparison of different variables, $p$-value $<0.05$ was considered significant.

\section{RESULTS}

50 subjects were enrolled and interviewed for the survey, which were equally divided into $25(50 \%)$ malesand $25(50 \%)$ females. The mean age of the participants was $32.15 \pm 2.63$ years. The mean age for males was $26.0 \pm$ 3.2 years and for females $35 \pm 5.0$ years. In this study there were $22(44 \%)$ married participants, $15(30 \%)$ hypertensive, $11(22 \%)$ smokers and $28(56 \%)$ have family history of hypertension(Table 1).

Table 1:Background characteristics of the study subjects.

\begin{tabular}{|c|c|c|c|}
\hline \multirow{2}{*}{\multicolumn{2}{|c|}{$\begin{array}{l}\text { Variables } \\
\text { Age Group (years) }\end{array}$}} & Frequency & $\%$ \\
\hline & & \multicolumn{2}{|c|}{$32.15 \pm 2.63$ (Age Rang $20-50$ years) } \\
\hline \multirow{2}{*}{ Gender } & Male & 25 & $50 \%$ \\
\hline & Female & 25 & $50 \%$ \\
\hline \multirow{3}{*}{ Age Group } & $20-30$ & 14 & $8 \%$ \\
\hline & $30-40$ & 27 & $54 \%$ \\
\hline & $40-50$ & 9 & $38 \%$ \\
\hline \multirow{3}{*}{ Marital Status } & Unmarried & 18 & $36 \%$ \\
\hline & Married & 22 & $44 \%$ \\
\hline & Others & 10 & $20 \%$ \\
\hline \multicolumn{4}{|l|}{ Risk Factors } \\
\hline \multirow{3}{*}{ Hypertension } & Yes & 15 & $30 \%$ \\
\hline & No & 28 & $56 \%$ \\
\hline & Don't Know & 7 & $14 \%$ \\
\hline \multirow{2}{*}{ Smoking } & Yes & 11 & $22 \%$ \\
\hline & No & 39 & $78 \%$ \\
\hline \multirow{2}{*}{ Family History } & Yes & 28 & $56 \%$ \\
\hline & No & 22 & $44 \%$ \\
\hline
\end{tabular}

Table 2: Frequency distribution of most popular drug group prescribed by Physicians

\begin{tabular}{|l|l|l|}
\hline Variable & F & $\%$ \\
\hline Type of Therapy & 35 & $70 \%$ \\
\hline Single Drug Therapy & 15 & $30 \%$ \\
\hline Multi Drug Therapy & & \\
\hline Drug Group & 21 & $42 \%$ \\
\hline ACE Inhibitors & 21 & $42 \%$ \\
\hline Beta-Blockers & 8 & $16 \%$ \\
\hline Diuretics & &
\end{tabular}

Table 3: Details of Medicine Prescribed by Physicians in Single and Multi DrugTherapy

\begin{tabular}{|c|c|c|}
\hline Variable & $f$ & $\%$ \\
\hline \multicolumn{3}{|l|}{ Single Drug Therapy } \\
\hline Propanolol & 6 & $12 \%$ \\
\hline Bisoprolol & 5 & $10 \%$ \\
\hline Captopril & 11 & $22 \%$ \\
\hline Lisinopril & 6 & $12 \%$ \\
\hline Indral & 6 & $12 \%$ \\
\hline Lozartan & 5 & $10 \%$ \\
\hline Hydrochlorothiazide & 9 & $18 \%$ \\
\hline Nebivolol & 2 & $4 \%$ \\
\hline \multicolumn{3}{|l|}{ Multi Drug Therapy } \\
\hline Ezetimibe & 5 & $10 \%$ \\
\hline Clopidogril & 4 & $8 \%$ \\
\hline Atenolol & 3 & $6 \%$ \\
\hline Captopril & 7 & $14 \%$ \\
\hline Telmisarton & 3 & $6 \%$ \\
\hline Aspirin & 4 & $8 \%$ \\
\hline Enalapril & 5 & $10 \%$ \\
\hline Spirolactone & 12 & $24 \%$ \\
\hline Metoprolol & 7 & $14 \%$ \\
\hline
\end{tabular}

Findings indicated that $35(70 \%)$ hypertensive patients were treated with single drug therapy while $15(30 \%)$ with multi drugs. ACE Inhibitors and Beta-Blockers were equally 
advised by physicians as $21(42 \%)$ and Diuretics $6(15 \%)$ (Table 2).

Most popular drug prescribed by physicians was Captopril 11(22\%) in single drug and in multi drugSpirolactone medicine was $12(24 \%)$. (Table 3)

\section{Graph -1:}

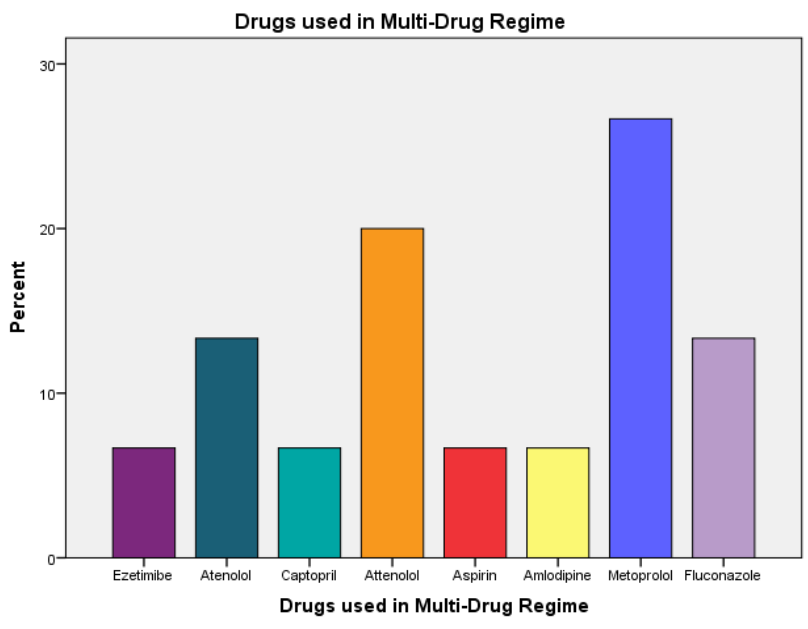

Graph -2:

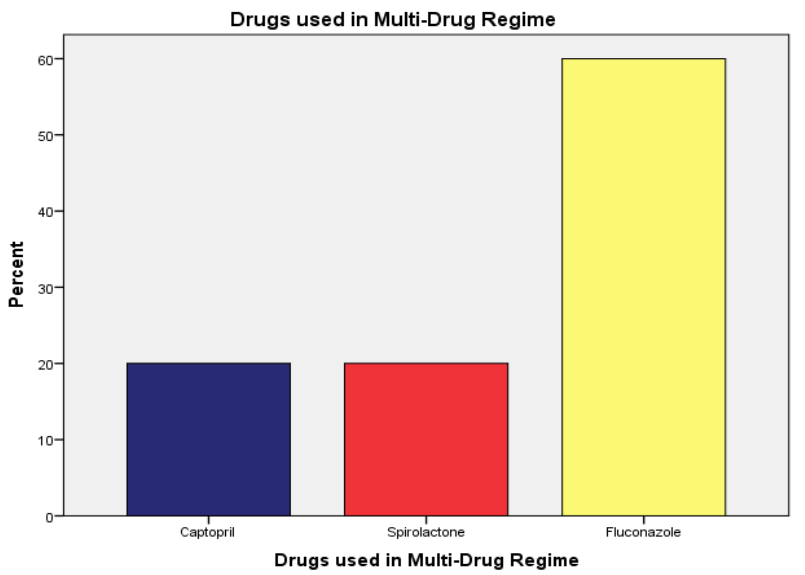

\section{DISCUSSION}

Hypertension is one of the most serious public health issues in both developed and emerging nations. We reported estimates of the prevalence of hypertension in the adult Pakistani population in this detailed systematic study. Currently, there is a deficiency of data on the prevalence of hypertension on a national scale. Only one current review, which focused on hypertension in Asian nations, was discovered in domestic and international literature searches. ${ }^{(12)}$

The current study was a cross-sectional, quantitative, descriptive study with data collected at one point from Medical Students of Lahore Medical and Dental College Lahore. The target and study populations essentially had similar characteristics.
In present study total 50 research subjects were interviewed and male and female ratio was $50 \%$. The average age $( \pm S D)$ of the study subject was $32.15( \pm 2.63)$ years and for male and female, it was $26.0( \pm 3.2)$ years and $35( \pm 5.0)$ years, respectively. Majority of the study subjects were married 22(44\%), 15(30\%) participants were hypertensive and smoker $11(22 \%)$ and have family history of hypertension.

Singh et al. (2017) conducted a meta-analysis and discovered that 42,618 people matched the qualifying criteria. Hypertension was found to be prevalent in 26.34 percent of the population. Males accounted for 24.99 percent of the population, while females accounted for 24.76 percent. When compared to data published in local and foreign publications, they found a significant prevalence of hypertension among adult Pakistanis: 23.32 percent and 27.44 percent, respectively. We also discovered that the prevalence of hypertension differed between small, medium, and large trials. ${ }^{(12)}$

HTN in women was also shown to be somewhat higher than men. Many additional studies have indicated that women have a higher prevalence of hypertension than men. Our findings contradict earlier published data. In highincome nations, women have better detection, treatment, and control rates than males, owing to the fact that pregnant women have more chances to have their blood pressure monitored.

For reducing high blood pressure, a variety of medicines are available, including diuretics, -blockers, CCBs, ACE inhibitors, and ARBs. These medications have been shown to decrease the disease and death rate associated with hypertension. ${ }^{(13)}$

The results of current study indicated that $35(70 \%)$ hypertensive patients were treated with single drug therapy as compare with multi drug 15(30\%). ACE Inhibitors and Beta-Blockers were equally prescribed by physicians as $21(42 \%)$ and Diuretics 6(15\%) used to management.

Most popular drug prescribed by physicians was Captopril 11(22\%) in single drug and in multi drugSpirolactone medicine was $12(24 \%)$.

Although there is no obvious pharmacological rationale for the combined use of an ACE inhibitor and a beta-blocker in the treatment of hypertension, Hansson (1989) conducted a study that demonstrated that this combination is more effective than monotherapy in a number of studies, some of which are reviewed. Furthermore, research suggests that this combination may be helpful following a myocardial infarction. As a result, the usage of an ACE inhibitor in conjunction with a betablocker should be investigated further. ${ }^{(14)}$

Nguyen et al. (2010) conducted study and found that if lifestyle changes are ineffective in bringing blood pressure back to normal, drug therapy is necessary. Diuretics, ACE inhibitors or ARBs, beta-blockers, and CCBs are among the first-line medicines used to treat hypertension. To attain their blood pressure desired level, some individuals will require two or more antihypertensive drugs.After using the first medicine at the maximum prescribed dose, a second drug with a complimentary mode of action should be added to reduce adverse effects. (15) 
A CCB plus an ACE inhibitor combo is also highly helpful, according to the ACCOMPLISH research.Concurrent use of an ACE inhibitor and an ARB is not recommended, even though it is seldom used in heart failure or diabetic patients with severe proteinuria. As proven by the ONTARGET investigation, there is an increased chance of adverse effects. In this research, patients who took an ACE inhibitor and an ARB at the same time had a significantly increased risk of low blood pressure and renal dysfunction. Some of the ineffectual beta-blockers include ACE inhibitors, beta-blockers/alphablockers or agonists, and beta-blockers/nondihydropyridines. ${ }^{(15)}$

\section{CONCLUSION}

Although hypertension is a global epidemic, there are numerous recommendations and pharmaceutical alternatives available to reduce the disease's morbidity and mortality. Despite the fact that lifestyle modification is commonly ignored but these changes should be implemented early and maintained permanently. Some people will have need of more than one antihypertensive medication to keep BP under control. In combination treatments are successful and recommended. The most crucial component of treating hypertension, regardless of whether medicine is used, is lowering blood pressure to the target level. In order to treat patients effectively, physicians, other healthcare providers, and patients must communicate effectively.

Conflict of Interest: The authors declare no conflict of interest.

\section{REFERENCE}

1. Young V, Rajeswaran S. Update on Portal Hypertension: Management of Portal Hypertension in the Pediatric Population: A Primer for the Interventional Radiologist. InSeminars in interventional radiology 2018 Aug (Vol. 35, No. 3, p. 160). Thieme Medical Publishers.

2. World Health Organization. A global brief on hypertension: silent killer, global public health crisis: World Health Day 2013. World Health Organization; 2013.

3. Nguyen Q, Dominguez J, Nguyen L, Gullapalli N. Hypertension management: an update. American health \& drug benefits. 2010 Jan;3(1):47.
4. World Health Organization, International Society of Hypertension Writing Group. 2003 World Health Organization (WHO)/International Society of Hypertension (ISH) statement on management of hypertension. Journal of hypertension. 2003 Nov 1;21(11):1983-92.

5. Bethge M, von Groote P, Giustini A, Gutenbrunner C. The World Report on Disability: a challenge for rehabilitation medicine. American journal of physical medicine \& rehabilitation. 2014 Jan 1;93(1):S4-11.

6. Shah N, Shah Q, Shah AJ. The burden and high prevalence of hypertension in Pakistani adolescents: a meta-analysis of the published studies. Archives of public health. 2018 Dec;76(1):1-0.

7. Riaz M, Shah G, Asif M, Shah A, Adhikari K, Abu-Shaheen A. Factors associated with hypertension in Pakistan: A systematic review and meta-analysis. PloS one. 2021 Jan 29;16(1):e0246085.

8. National High Blood Pressure Education Program, The seventh report of the Joint National Committee on prevention, detection, evaluation, and treatment of high blood pressure, 2004

9. Nguyen Q, Dominguez J, Nguyen L, Gullapalli N. Hypertension management: an update. American health \& drug benefits. 2010 Jan;3(1):47.

10. Almas A, Ehtamam A, Khan AH. Spectrum of antihypertensive therapy in South Asians at a tertiary care hospital in Pakistan. BMC research notes. 2011 Dec;4(1):16.

11. Shah N, Shah Q, Shah AJ. The burden and high prevalence of hypertension in Pakistani adolescents: a meta-analysis of the published studies. Archives of public health. 2018 Dec;76(1):1-0..

12. Singh S, Shankar R, Singh GP. Prevalence and associated risk factors of hypertension: a cross-sectional study in urban Varanasi. International journal of hypertension. 2017 Oct;2017.

13. Addo J, Smeeth L, Leon DA. Hypertension in sub-saharan Africa: a systematic review. Hypertension. 2007 Dec 1;50(6):1012-8.

14. Hansson L. Beta-blockers with ACE inhibitors--a logical combination?. Journal of human hypertension. 1989 Jun 1;3:97-100.

15. Nguyen Q, Dominguez J, Nguyen L, Gullapalli N. Hypertension management: an update. American health \& drug benefits. 2010 Jan;3(1):47. 